Received 12/29/2019 Review began 01/02/2020 Review ended $01 / 03 / 2020$ Published 01/05/2020 Corrected 01/07/2020

(c) Copyright 2020

Albugami et al. This is an open access article distributed under the terms of the Creative Commons Attribution License CCBY 3.0., which permits unrestricted use, distribution, and reproduction in any medium, provided the original author and source are credited.

\section{Corrected: The Perception of Coronary Artery Disease and Cardiac Catheterization in Saudi Arabia: "What the Public Know"}

Saad Albugami ${ }^{1}$, Faisal Al-Husayni ${ }^{2}$, Lama Bakhsh ${ }^{2}$, Faisal Alhameed ${ }^{3}$, Ahmad Alsulami ${ }^{3}$, Khalid Abumelha ${ }^{3}$, Marwan Balubaid ${ }^{3}$, Maha Al-Harbi ${ }^{4}$, Hani N. Mufti 5, 6, 7

1. Cardiac Sciences / Interventional Cardiology, King Faisal Cardiac Center, King Saud Bin Abdulaziz University for Health Sciences / King Abdullah International Research Center, Jeddah, SAU 2. Internal Medicine, National Guard Hospital, Jeddah, SAU 3. Internal Medicine, King Saud Bin Abdulaziz University for Health Sciences, Jeddah, SAU 4. Nursing, National Guard Hospital, Jeddah, SAU 5. Cardiac Sciences / Cardiac Surgery, King Faisal Cardiac Center, King Saud Bin Abdulaziz University for Health Sciences / King Abdullah International Research Center, Jeddah, SAU 6. Research Unit, King Abdullah International Medical Research Center, Jeddah, SAU 7. College of Medicine, King Saud Bin Abdulaziz University for Health Sciences, Jeddah, SAU

Corresponding author: Saad Albugami, sbugami@yahoo.com

\section{This article has been corrected.}

Correction date: January 07, 2020. Cite this correction as Albugami S, Al-Husayni F, Bakhsh L, et al. (January 07, 2020) Correction: The Perception of Coronary Artery Disease and Cardiac Catheterization in Saudi Arabia: “What the Public Know”. Cureus 12(1): c27. doi:10.7759/cureus.c27.

Figure 5 was initially portrayed as a pie chart, but has been updated to a bar chart as the percentages exceed $100 \%$ and this is in line with the other charts used in the study.

\section{Abstract \\ Objective}

Coronary artery disease (CAD) constitutes a significant health hazard in middle-aged individuals in Saudi Arabia. We sought to assess the level of knowledge of cardiovascular risk factors and describe the perception of coronary intervention among the general population in the city of Jeddah in the western part of Saudi Arabia.

\section{Methods}

A cross-sectional study was conducted in the city of Jeddah during the period from April 2019 to September 1, 2019, by using a structured online questionnaire to assess the participants' awareness of risk factors for $\mathrm{CAD}$ and coronary intervention. The survey included questions about socio-demographic data, risk factors of cardiovascular diseases, symptoms of heart attack, knowledge of coronary catheterizations, as well as resources of knowledge about coronary heart disease.

\section{Results}

The study included 984 participants. The majority of the participants had university diplomas (78.1\%). Only $38.5 \%$ were healthcare workers. Dyslipidemia and smoking were identified by $70.5 \%$ and $66.7 \%$, respectively, as a recognized risk factor for CAD. Diabetes was mentioned by $32.1 \%$. Participants without CAD risk factors had a significantly lower level of knowledge regarding the strong association between diabetes mellitus (DM) II and CAD ( $p$-value $=0.02$ ). Healthcare professionals had a significantly lower level of knowledge regarding cardiac catheterization as compared to non-healthcare professionals. A higher percentage of healthcare professionals would agree to have cardiac catheterization if indicated ( $\mathrm{p}$-value $=0.003$ ). Awareness campaigns were the most common source of information for the public.

\section{Conclusion}

The current level of knowledge of CAD in the western part of Saudi Arabia is fair. National awareness campaigns are required to improve the level of healthcare education.

Categories: Cardiology

Keywords: coronary artery diseases, cardiac catheterization, awareness, cardiovascular disease, survey, knowledge, perception

\section{Introduction}




\section{Cureus}

Cardiovascular diseases (CVDs) are considered the leading cause of morbidity and mortality globally. They are regarded as the primary cause of extended hospital stays and increased healthcare costs [1-5]. More people die annually from CVDs than from any other cause. An estimated 17.9 million people died from CVDs in 2016, representing $31 \%$ of all global deaths. Of these deaths, $85 \%$ were due to heart attacks and stroke. Over three-quarters of CVD deaths take place in low and middle-income countries. Based on epidemiological data, cardiovascular diseases will remain the leading cause of mortality and morbidity throughout the next decade [2-7]. The mean age for developing CAD in the Middle East is 10 years younger than the mean age of their western counterparts [2-8]. The prevalence of CAD risk factors among Saudi patients with established CAD is alarming; however, many of these are modifiable risk factors [9-11]. In Saudi Arabia, despite the widespread availability of hospitals with a catheterization laboratory, there are fewer patients treated with a primary percutaneous intervention [12]. The baseline knowledge about CVD among the general population has a significant public impact in developing targeted educational programs [13]. Knowledge of CVDs, its symptoms, and its risk factors have been studied worldwide in various populations [14]. Nevertheless, there is a scarcity of data in Saudi Arabia on the perception of the Saudi public of coronary artery disease (CAD) and coronary catheterization. Therefore, this study aims to examine the level of knowledge and perception of the public towards coronary artery disease and its treatment in an attempt to generate educational programs to reduce the CVDs burden.

\section{Materials And Methods}

This was a cross-sectional study conducted at King Saud bin Abdulaziz University for Health Sciences in Jeddah, Saudi Arabia, during the period from April 2019 to September 1, 2019. This was achieved through voluntary participation in an online survey questionnaire that was constructed in the Arabic language. Participants were asked to distribute the survey to their friends and relatives.

The sample size was calculated assuming that we are targeting a sample from only the city of Jeddah, which has an estimated total population of four million inhabitants, with a $99 \%$ confidence level and a $5 \%$ margin of error; the sample size was determined to be 665 respondents. All volunteer participants who were able to complete the online survey were included. Participants younger than 18 years of age and who could not or did not complete the survey were excluded. The questionnaire was adapted and modified from a previous survey by Almalki et al. [15]. We collected sociodemographic characteristics, assessments of awareness of $\mathrm{CAD}$ risk factors, coronary angiography, and CAD treatment. Socioeconomic variables were participants' age, sex, nationality, marital status, employment, education, and income. Family and personal medical histories, such as diabetes mellitus (DM), hypertension, and dyslipidemia (high cholesterol or triglycerides levels) were collected as well. Awareness of CAD risk factors was assessed through yes or no questions asking whether or not the participants believed certain factors were considered risk factors for CAD. The survey also included questions on symptoms of a heart attack, information about cardiac catheterization, and resources of information about coronary artery disease (See Table 1 for complete survey questions). The study was conducted following the Declaration of Helsinki. It received ethical approval from the Institutional Review Board of King Abdullah International Medical Research Center.

\section{Socio-demographics Section}

Age

18 to 25

26 to 35

36 to 45

46 to 55

56 to 65

Above 65

Gender Male

Female

Marital Status

Married

Unmarried

Level of education

Diploma or university 


\section{Cureus}

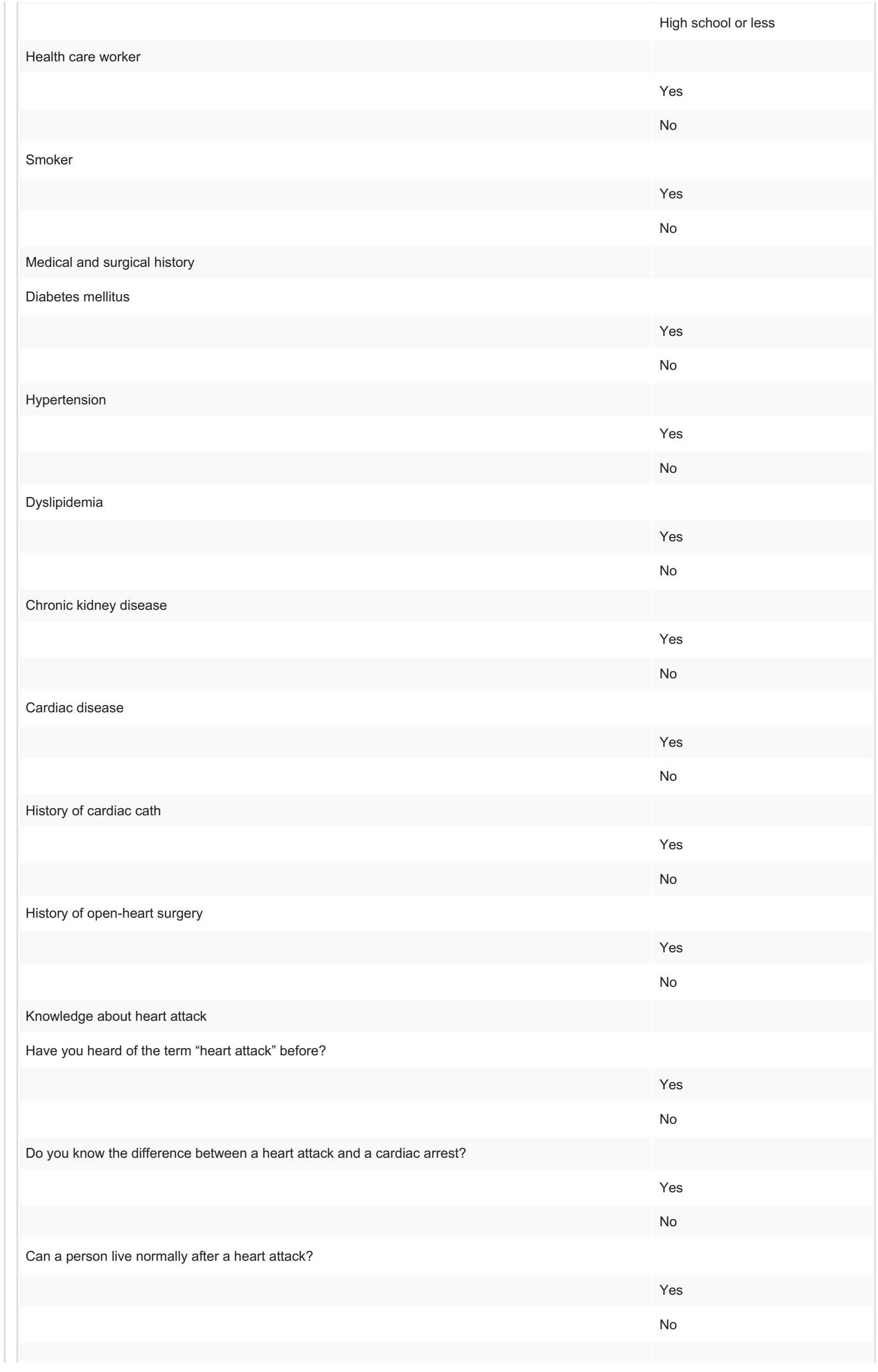




\section{Cureus}

Do females have more heart attacks than males?

Yes

No

If someone has a heart attack, does he/she need to go to the hospital by himself/herself and not wait for an ambulance?

Can a heart attack happen to someone younger than 30 years old?

Yes

No

Which of the following is a risk factor of coronary artery disease? (You may choose more than one)

Diabetes

Hypertension

Dyslipidemia

Smoking

Overweight

Aging

Sedentary Lifestyle

Unhealthy diet

Genetics

Anger

Do not know

Which of the following is a symptom of a heart attack? (You may choose more than one)

Chest pain

Shortness of breath

Jaw or arm pain

Nausea and vomiting

Pins and needles sensation in the chest

Palpitations

Sweating

Dizziness

Do not know

Which of the following is a coronary artery disease diagnostic method? (You may choose more than one)

History and physical exam
Blood tests
Imaging
Stress test
Cardiac catheterization
Heart biopsy




\section{Cureus}

\begin{tabular}{|c|c|}
\hline \multirow{3}{*}{ Which of the following is a treatment of coronary artery disease? (You may choose more than one) } & \multirow{2}{*}{$\begin{array}{l}\text { ECG } \\
\text { Do not know }\end{array}$} \\
\hline & \\
\hline & \\
\hline & Anticoagulants \\
\hline & Thrombolytics \\
\hline & Vasodilators \\
\hline & $\begin{array}{l}\text { Medications to decrease blood } \\
\text { pressure }\end{array}$ \\
\hline & $\begin{array}{l}\text { Medications to decrease heart } \\
\text { rate }\end{array}$ \\
\hline & Medications to decrease lipids \\
\hline & Cardiac catheterization \\
\hline & Open-heart surgery \\
\hline & Do not know \\
\hline \multicolumn{2}{|l|}{ Knowledge of cardiac catheterization } \\
\hline \multicolumn{2}{|l|}{ Do you know the difference between diagnostic and therapeutic catheterization? } \\
\hline & Yes \\
\hline & No \\
\hline \multicolumn{2}{|l|}{ Who does the cardiac catheterization? } \\
\hline & Any doctor \\
\hline & Cardiac surgeon \\
\hline & Interventional cardiologist \\
\hline & Do not know \\
\hline \multicolumn{2}{|l|}{ Is contrast used in cardiac catheterization? } \\
\hline & Yes \\
\hline & No \\
\hline & Do not know \\
\hline \multicolumn{2}{|l|}{ What is the access used in cardiac catheterization? } \\
\hline & Arm or thigh vessels \\
\hline & Mouth \\
\hline & $\begin{array}{l}\text { Directly through the skin to the } \\
\text { heart }\end{array}$ \\
\hline & Do not know \\
\hline \multicolumn{2}{|l|}{ Can a cardiac catheterization be a one-day procedure? } \\
\hline & Yes \\
\hline & No \\
\hline & Do not know \\
\hline \multicolumn{2}{|l|}{ Can a stent be inserted using catheterization? } \\
\hline & Yes \\
\hline & No \\
\hline & Do not know \\
\hline
\end{tabular}




\section{Cureus}

Source of information

Which of the following is your source of information about coronary artery disease? (You may choose more than one)

Doctors

Internet

Media and social media

Campaigns

Books

Patients with cardiac disease

\section{TABLE 1: Survey questions}

Translated from the Arabic language

\section{Statistical analysis}

The results of this survey are mainly descriptive of the perception and knowledge of CAD and cardiac catheterization in a contemporary sample from Jeddah, Saudi Arabia. In this survey, data were reported mostly in the form of frequencies and the percentage of respondents. Categorical variables were analyzed by $\chi 2$ (chi-square) or Fisher's exact test as appropriate. The Kruskal-Wallis test was used for ordinal variables. Statistical analysis was performed using the Fisher exact test to evaluate the significance of some of the survey results. Values of $\mathrm{p}<0.05$ were considered significant. All statistical analysis and assessment of the model's performance were conducted using the R-Software, version 3.3.0 (R Project for Statistical Computing, Vienna, Austria) [16].

\section{Results}

There were 984 responders to the study survey. The participants were well-educated and relatively young. There were $54.5 \%$ females. The majority had university diplomas or higher (78.1\%). Two-thirds of the participants were younger than 45 years of age. The prevalence of CAD risk factors among the study group was low; 9.6\% had type two diabetes, $9.2 \%$ had hypertension, $7.7 \%$ had dyslipidemia, and $18.2 \%$ were smokers. Only $3.9 \%$ of the study group had CAD; $38.5 \%$ of the cohorts were health care workers (Table 2).

\section{Variable}

Frequency (\%)

Age (Years)

18 to 25

26 to 35

36 to 45

46 to 55

56 to 65

Above 65

Gender

Male

Female

Marital Status

Married

Unmarried

306 (31.1)

Educational Level 


\section{Cureus}

Diploma or University

769 (78.2)

Health Care Worker

Yes

No

History of Smoking

Yes

No

History of Diabetes Mellitus

Yes

No

History of Hypertension

Yes

No

History of Chronic Kidney Disease

Yes

No

History of Dyslipidemia

Yes

No

History of Cardiac Disease

Yes

No

History of Cardiac Cath

Yes

No

History of Open-Heart Surgery

Yes

No

979 (99.5)

TABLE 2: Respondents demographics (total number of respondents=984)

The following responses to the questions on heart attack were obtained; $92.2 \%$ had heard of the term. Most participants (almost 82\%) were able to differentiate between heart attack and cardiac arrest. Three-quarters mentioned that patients who suffered a heart attack could live normally. Almost two-thirds of the participants would not wait for emergency services arrival and would immediately drive themselves to the nearest hospital if they suffered a heart attack. Nearly three-quarters of the participants (72\%) believed that a heart attack could occur in a person younger than the age of 30 (Table 3). 


\section{Cureus}

\begin{tabular}{|c|c|c|c|}
\hline & Response & Frequency & Percent \\
\hline \multirow[t]{2}{*}{ Heard of heart attack before } & No & 76 & 7.7 \\
\hline & Yes & 908 & 92.2 \\
\hline \multirow[t]{2}{*}{ Knows the difference between heart attack and cardiac arrest } & No & 181 & 18.3 \\
\hline & Yes & 803 & 81.6 \\
\hline \multirow[t]{2}{*}{ Can a person live normally after a heart attack } & No & 258 & 26.2 \\
\hline & Yes & 726 & 73.7 \\
\hline \multirow[t]{3}{*}{ Females have more heart attacks than males } & No & 293 & 29.7 \\
\hline & Yes & 176 & 17.8 \\
\hline & Don't know & 515 & 52.3 \\
\hline \multirow[t]{3}{*}{ Should go to the hospital and not wait for an ambulance when experiencing a heart attack } & No & 169 & 17.1 \\
\hline & Yes & 598 & 60.7 \\
\hline & Don't know & 214 & 21.7 \\
\hline \multirow[t]{3}{*}{ Heart attack could happen in people younger than 30 years old } & No & 57 & 5.7 \\
\hline & Yes & 710 & 72.1 \\
\hline & Don't know & 217 & 22.0 \\
\hline
\end{tabular}

TABLE 3: General questions about heart attack

Responses to the coronary artery disease risk factors were as follows: $70.5 \%$ of the participants agreed that dyslipidemia is a risk factor for coronary artery disease, followed by smoking (66.7\%), while diabetes was recognized by only $32.22 \%$ of the respondents. Five percent of the participants did not know CAD risk factors, as shown in Figure 1.

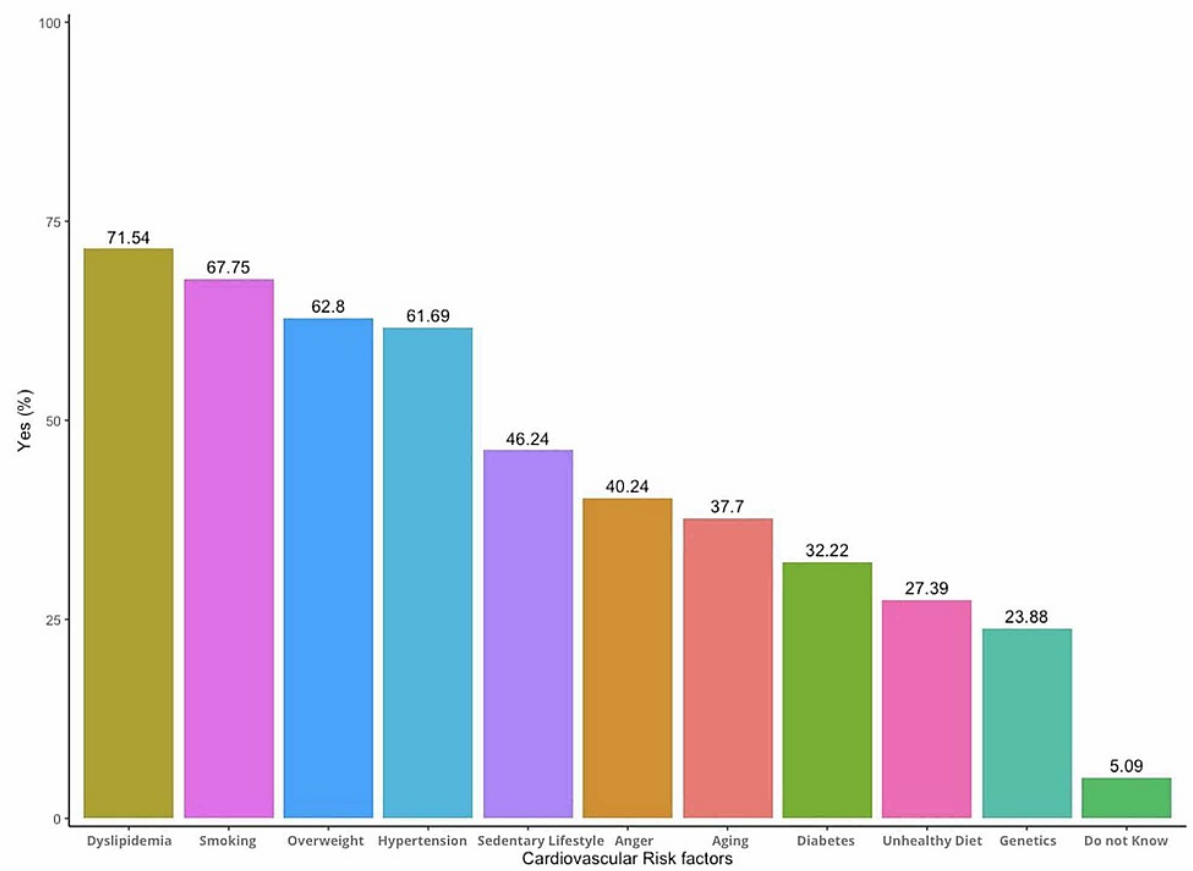

FIGURE 1: Responses to risk factors of coronary artery disease 


\section{Cureus}

The participants' perception of the symptoms of a heart attack is shown in Figure 2. Of the responders, $74.3 \%$ revealed that chest pain or heaviness is a common symptom of a heart attack, followed by dyspnea (59.1\%), loss of consciousness (59.1\%), sweating (39.4\%), palpitations (34\%), and jaw pain (36.2\%). Other associated symptoms like nausea and vomiting were mentioned. Only $13 \%$ of responders did not know the common symptoms of a heart attack.

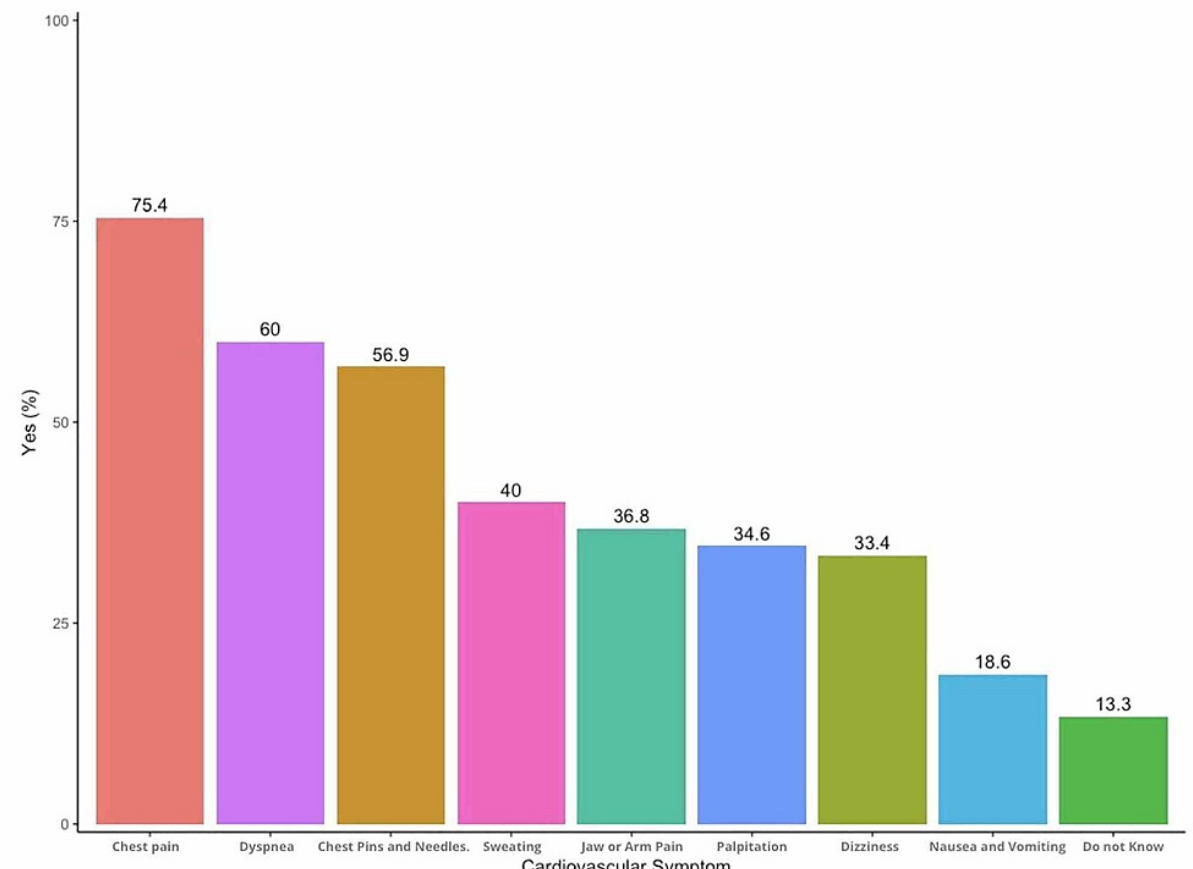

FIGURE 2: Responses to symptoms of a heart attack

Figure 3 shows the perception of the diagnostic tests by the participants. Sixty-four percent mentioned that an electrocardiogram is the best test, followed by a stress test, imaging, and coronary angiography. Fifty-six percent of the cohort agreed that cardiac catheterization and coronary intervention are the best treatment for CAD, followed by anticoagulants (51.8\%) and then thrombolytics (44.9) while only $17.2 \%$ were unaware of any treatment options (Figure 4).

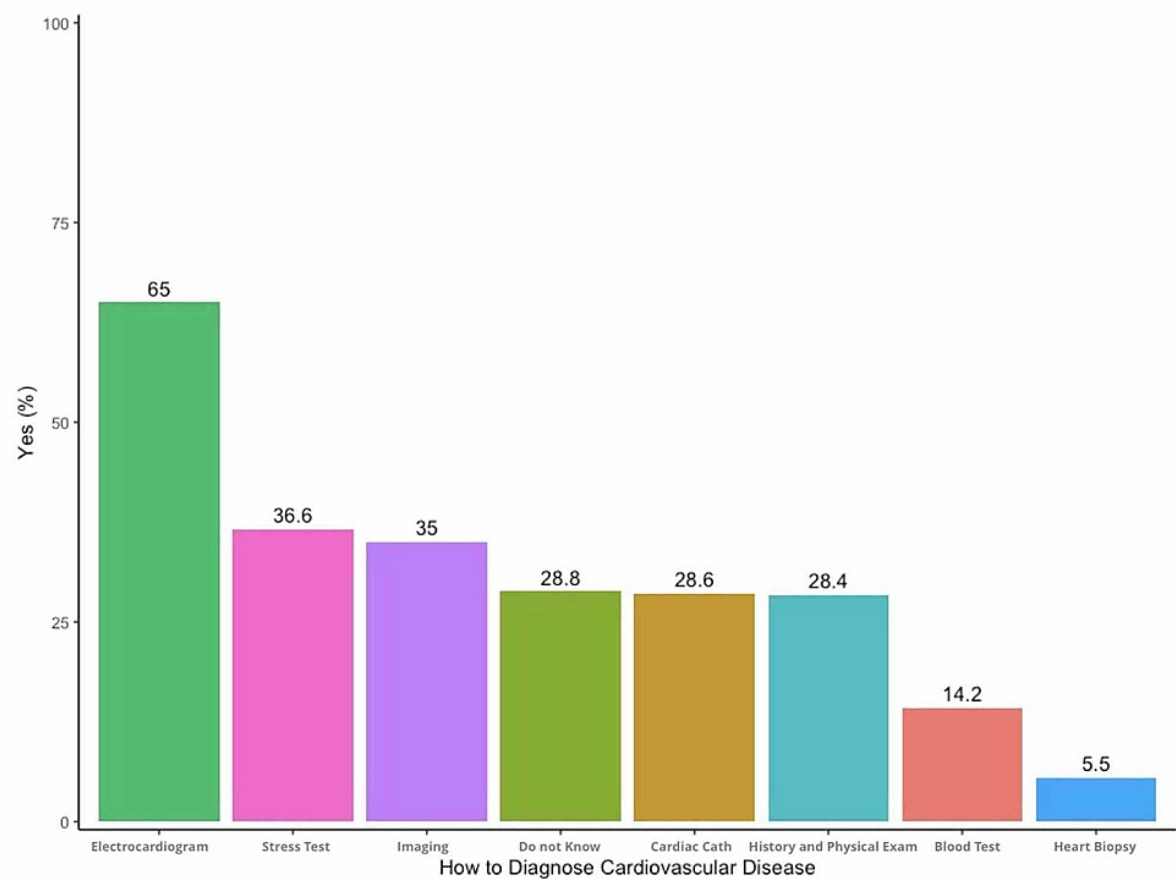

FIGURE 3: Responses to the diagnosis of coronary artery disease 


\section{Cureus}

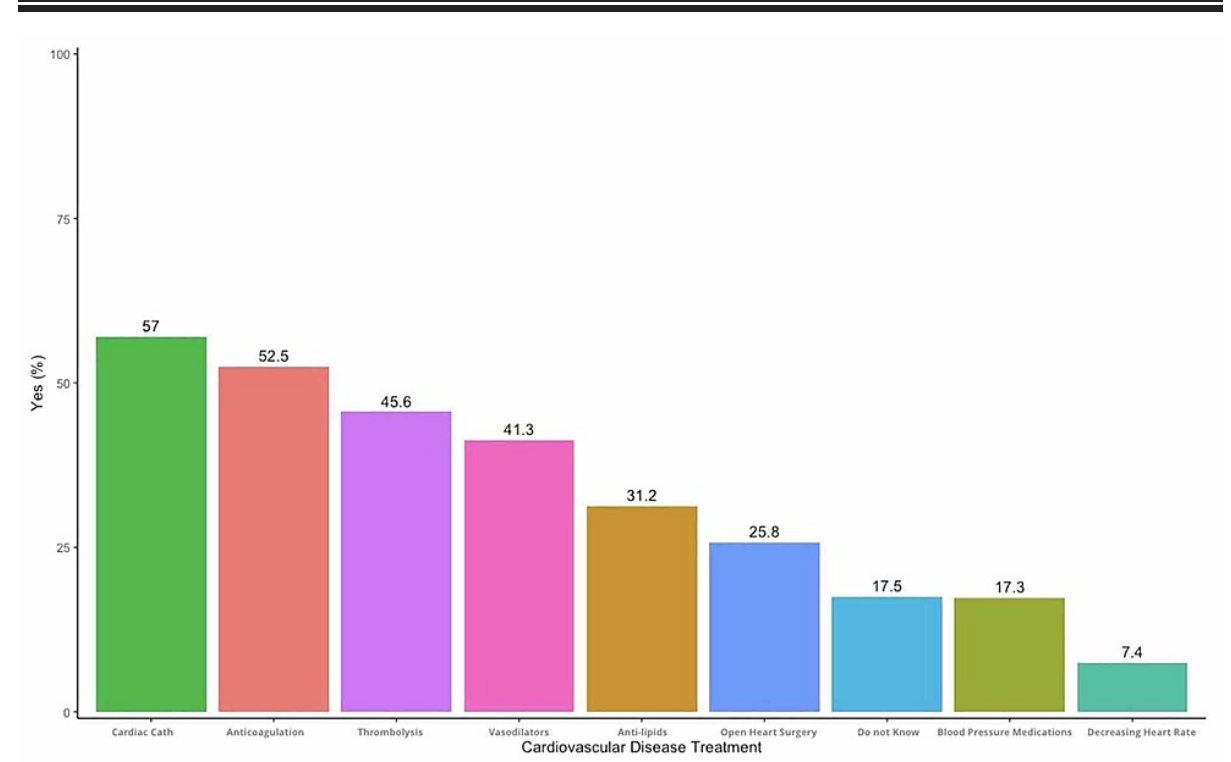

FIGURE 4: Responses to the treatment of coronary artery disease

Thirty percent were able to know the difference between diagnostic and therapeutic catheterization. Out of the 984 participants, $47.3 \%$ thought that cardiac catheterization is performed by a cardiac surgeon and $16.5 \%$ thought that it is done by an interventional cardiologist. Contrast use during the procedure was mentioned by $61.7 \%$. Catheterization access was reported to be the arm or thigh blood vessels by $60.8 \%$. Five percent thought it is done through the chest wall directly into the heart and 3.4\% thought it was through the mouth. The majority of the participants $(78.3 \%)$ would agree to have a cardiac catheterization if needed while $4.5 \%$ did not agree and $17.0 \%$ were ambivalent about whether to accept or not (Table 4). 


\section{Cureus}

\begin{tabular}{|c|c|c|}
\hline & Response & Frequency, (\%) \\
\hline \multirow[t]{2}{*}{ Knows the difference between diagnostic and therapeutic catheterization } & No & $684(69.5 \%)$ \\
\hline & Yes & $300(30.4 \%)$ \\
\hline \multirow[t]{4}{*}{ Who does the catheterization } & Any doctor & $58(5.8 \%)$ \\
\hline & cardiac surgeon & $466(47.3 \%)$ \\
\hline & Interventional cardiologist & $163(16.5 \%)$ \\
\hline & Don't know & $297(30.1 \%)$ \\
\hline \multirow[t]{3}{*}{ Use of contrast in the catheterization } & No & $102(10.3 \%)$ \\
\hline & Yes & $274(27.8 \%)$ \\
\hline & Don’t know & $608(61.7 \%)$ \\
\hline \multirow[t]{4}{*}{ What is the access of the catheterization } & Arm or thigh vessels & $599(60.8 \%)$ \\
\hline & Mouth & $34(3.4 \%)$ \\
\hline & Directly through to the heart & $50(5.0 \%)$ \\
\hline & Don't know & $301(30.5 \%)$ \\
\hline \multirow[t]{3}{*}{ Can a catheterization be a one-day procedure } & No & $310(31.5 \%)$ \\
\hline & Yes & $385(39.1 \%)$ \\
\hline & Don't know & $289(29.3 \%)$ \\
\hline \multirow[t]{3}{*}{ Can stent be inserted using a catheterization } & No & $29(2.9 \%)$ \\
\hline & Yes & $613(62.2 \%)$ \\
\hline & Don't know & $342(34.7 \%)$ \\
\hline \multirow[t]{3}{*}{ Would you agree on a catheterization if needed? } & No & $45(4.5 \%)$ \\
\hline & Yes & $771(78.3 \%)$ \\
\hline & Don't know & $168(17.0 \%)$ \\
\hline
\end{tabular}

\section{TABLE 4: Responses to questions on cardiac catheterization}

We attempted to assess the difference in perception of cardiac disease risk factors and symptoms between respondents who had at least one cardiac risk factor (diabetes, hypertension, dyslipidemia, or smoking) as compared to respondents who had no cardiac risk factors. It was counterintuitive to notice that more participants who had CAD risk factors had poor knowledge of heart attack symptoms, as shown in Table 5. Interestingly, when assessing common cardiac risk factors, there were no differences between the two groups except that respondents who had no cardiac risk factors were less likely to think that diabetes is a recognized risk factor for cardiac disease ( $\mathrm{p}$-value $=0.012$ ). When we evaluated the knowledge of respondents on the most common cardiac symptoms, there were no differences except in nausea and vomiting. Respondents who had at least one cardiac risk factor were more likely to consider nausea and vomiting as a symptom of cardiac disease ( $\mathrm{p}$-value $=0.002)$ (Table 5). 


\section{Cureus}

Participants Who Have At Least 1 Cardiac

Risk Factor

Risk Factors

Diabetes is a Risk Factor

Hypertension is a Risk Factor

Dyslipidemia is a Risk Factor

Age is a Risk Factor

Overweight is a Risk Factor

Smoking is a Risk Factor

Sedentary Lifestyle is a Risk

Factor

Unhealthy Diet is a Risk

Factor

Genetics is a Risk Factor

Anger is a Risk Factor

Symptoms

Chest Pain
Dizziness
Nausea and Vomiting
Pain in the Jaw or Arm
Pins and Needles in the
Chest
Shortness of Breath
Sweating

Yes, $\mathrm{n}=\mathbf{3 5 7}$

(\%)

(\%)

(\%)

value

$131(36.7 \%)$

$185(29.6 \%)$

$316(32.1 \%)$

$<0.05^{*}$

$232(65 \%)$

$374(59.7 \%) \quad 606(61.6 \%)$

0.1

$263(73.7 \%)$

$126(35.3 \%)$

$440(70.3 \%)$

$703(71.5 \%)$

0.26

$229(64.1 \%)$

$244(39 \%)$

$370(37.6 \%)$

0.25

$252(70.6 \%$

$389(62.1 \%) \quad 618(62.9 \%)$

0.53

$413(66.1 \%) \quad 665(67.7 \%)$

0.15

$173(48.5 \%)$

$282(45 \%)$

$455(46.3 \%)$

$94(26.4 \%)$

$175(28 \%)$

$269(27.4 \%)$

0.6

$82(23 \%)$

$153(24.4 \%) \quad 235(23.9 \%)$

0.6

$156(43.7 \%)$

$240(38.3 \%) \quad 396(40.3 \%)$

0.09

\section{$267(74.8 \%)$}

$741(75.4 \%)$

0.7

$119(33.3 \%)$

$209(33.4 \%)$

$328(33.4 \%)$

0.9

$84(23.5 \%)$

$99(15.8 \%)$

$183(18.6 \%)$

$<0.05^{*}$

$136(38.1 \%)$

$225(35.9 \%)$

$361(36.7 \%)$

0.5

$114(31.9 \%) \quad 225(36 \%) \quad 339(34.5 \%) \quad 0.2$

$202(56.6 \%) \quad 357(57 \%) \quad 559(56.9 \%) \quad 0.9$

$207(58 \%) \quad 382(61 \%) \quad 589(59.9 \%) \quad 0.4$

$154(43.1 \%) \quad 239(38.2 \%) \quad 393(40 \%)$

\section{TABLE 5: Comparison of responders with at least one risk factor with those who have none}

${ }^{*} \mathrm{p}$-value at level of significance $<0.05$

Because almost $40 \%$ of the respondents were health care workers, we sought to determine whether they have a better knowledge of coronary catheterization as compared to the general public. Table 6 demonstrates the responses to the questions with regard to coronary catheterizations. Non-healthcare workers had better knowledge on several points. Health care workers had a higher rate of choosing the "Do not Know" answer (Table 6). Additionally, more healthcare professionals will agree to have a cardiac catheterization if indicated $(\mathrm{p}$-value $=0.005)$. 


\section{Cureus}

\begin{tabular}{|c|c|c|c|c|c|}
\hline Health Care Worker & & $\begin{array}{l}\text { Yes, n= } 379 \\
(\%)\end{array}$ & $\begin{array}{l}\text { No, } n=605 \\
(\%)\end{array}$ & $\begin{array}{l}\text { Total, n=984 } \\
\text { (\%) }\end{array}$ & $\begin{array}{l}\mathrm{p}- \\
\text { value }\end{array}$ \\
\hline Heard of Cardiac Cath & & $365(96.3 \%)$ & $581(96 \%)$ & $946(96 \%)$ & 0.8 \\
\hline $\begin{array}{l}\text { Knows the difference between diagnostic and } \\
\text { therapeutic cath }\end{array}$ & & $89(23.5 \%)$ & $211(34.9 \%)$ & $300(30.5 \%)$ & $<0.05^{*}$ \\
\hline \multicolumn{6}{|l|}{ Who does the cath } \\
\hline & Any Doctor & $23(6.1 \%)$ & $35(5.8 \%)$ & $58(5.9 \%)$ & 0.5 \\
\hline & Cardiac Surgeon & $181(47.8 \%)$ & $285(47.1 \%)$ & $466(47.4 \%)$ & \\
\hline & $\begin{array}{l}\text { Interventional } \\
\text { Cardiology }\end{array}$ & $55(14.5 \%)$ & $108(17.9 \%)$ & $163(16.6 \%)$ & \\
\hline & Don't know & $120(31.7 \%)$ & $177(29.3 \%)$ & $297(30.2 \%)$ & \\
\hline \multicolumn{6}{|l|}{ Use of contrast during a cardiac cath } \\
\hline & Yes & $98(25.9 \%)$ & $176(29.1 \%)$ & $274(27.8 \%)$ & $<0.05^{*}$ \\
\hline & Don't know & $252(66.5 \%)$ & $356(58.8 \%)$ & $608(61.8 \%)$ & \\
\hline \multicolumn{6}{|l|}{ Use of imaging during a cardiac cath } \\
\hline & Yes & $141(37.2 \%)$ & $254(42 \%)$ & $395(40.1 \%)$ & 0.054 \\
\hline & Don't know & $217(57.3 \%)$ & $302(49.9 \%)$ & $519(52.7 \%)$ & \\
\hline \multicolumn{6}{|l|}{ Cath can be done as a day case } \\
\hline & Yes & $127(33.5 \%)$ & $258(42.6 \%)$ & $385(39,1 \%)$ & $<0.05^{*}$ \\
\hline & Don't know & $114(30.1 \%)$ & $175(28.9 \%)$ & $289(29.4 \%)$ & \\
\hline \multicolumn{6}{|l|}{ Coronary Stent can be inserted during an angiogram } \\
\hline & Yes & $210(55.4 \%)$ & $403(66.6 \%)$ & $613(62.3 \%)$ & $<0.05^{*}$ \\
\hline & Don't know & 114 (30.1\%) & 175 (28.9\%) & $289(29.4 \%)$ & \\
\hline \multicolumn{6}{|l|}{ Will you agree to have angiogram if needed } \\
\hline & Yes & $296(78.1 \%)$ & 475 (78.5\%) & 771 (78.4\%) & $<0.05^{*}$ \\
\hline & Don’t know & $56(14.8)$ & 112 (18.5\%) & $168(17.1 \%)$ & \\
\hline
\end{tabular}

\section{TABLE 6: Cath knowledge by being a health care worker or not}

${ }^{*} p$-value at level of significance $<0.05$

Finally, participants were required to choose the source of information about CAD and cardiac catheterization. Fifty-three point five percent received their knowledge from health awareness campaigns while only 6.9\% received their information from books, as shown in Figure 5. 


\section{Cureus}

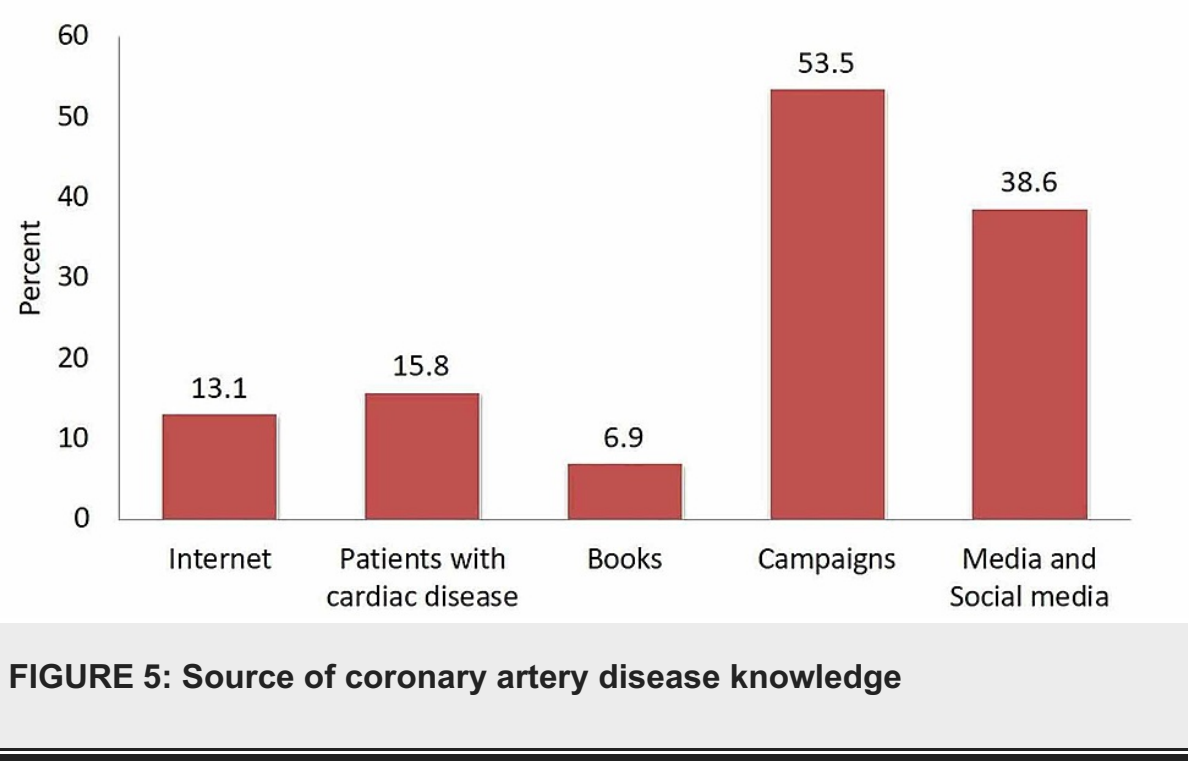

Discussion

The young population of Saudi Arabia is undergoing significant economic changes that have translated into the adoption of a Western dietary lifestyle that has led to a significant increase in the burden of cardiovascular diseases [17]. However, adequate baseline knowledge of CAD risk factors is lacking. Improved public awareness is associated with greater personal awareness and increased actions to lower CVD risk [18]. Knowledge related to heart disease has been associated with health promotion behaviors [19-20]. The study demonstrated fair knowledge of CAD risk factors and the role of coronary catheterization.

The majority of participants with or without CAD risk factors assumed that DM is the least likely to lead to the development of CAD. Participants without risk factors had significantly lower knowledge of the association between $\mathrm{DM}$ and $\mathrm{CAD}$ ( $\mathrm{p}$-value $=<0.05$ ). In contrast, many have recognized that dyslipidemia, hypertension, and smoking are risks for developing CAD. The study demonstrated poor knowledge of heart attack symptoms among patients with risk factors for CAD. While healthcare workers are more likely to accept undergoing coronary catheterization when required, they, had lower knowledge of aspects of cardiac catheterization as compared to non-healthcare professionals. Awareness campaigns seemed to be the most favorable source of information when learning about coronary heart disease and coronary catheterization among the population studied.

Almalki et al., in a recent study from Jeddah, reported a deficient level of awareness of CAD risk factors, DM, smoking, and lack of physical activity were identified by only $12 \%, 26 \%$, and $39 \%$ of participants, respectively [15].

De Oliveira et al., in a small study, showed that patients were perplexed in differentiating between therapeutic and diagnostic coronary angiograms. They have reported heightened fear and anxiety among patients who had coronary catheterization; this was attributed to a lack of adequate knowledge of the procedure [21].

On the other hand, Tait et al., in a study that included 151 patients who underwent a pre-catheterization educational program, reported an improved understanding of the procedure, which resulted in better patient experience [22]. It is clear that educational programs are needed to spread knowledge and enhance the public awareness of the risk factors of CAD and its treatment in order to be effective in reducing the overwhelming burden of this devastating disease.

\section{Limitations}

The present study has many limitations: voluntary self-reporting of risk factors, lack of questioner validation, and high response from the younger age group with a high level of education, which might not be representative of the entire social spectrum. All these factors limit the generalizability of the survey.

\section{Conclusions}

CAD disease is a significant health issue globally. Prevention can be achieved through the better control of the risk factors of atherosclerosis. Improved public knowledge will favorably contribute to the adoption of a better lifestyle that lessens the burden of CAD. Our study showed an explicit limited knowledge of CAD risk factors, symptoms, methods of diagnosis, and treatment among the Western population of Saudi Arabia. 
Additionally, it showed a lack of proper awareness of the role of coronary angiography and coronary interventions. Decision-makers in the Kingdom of Saudi Arabia are required to enhance public awareness through campaigns and screening programs.

\section{Additional Information \\ Disclosures}

Human subjects: Consent was obtained or waived by all participants in this study. King Abdullah International Research Center issued approval H-01-R-005. The study was approved by King Abdullah International Research Center; it met all required conditions. Animal subjects: All authors have confirmed that this study did not involve animal subjects or tissue. Conflicts of interest: In compliance with the ICMJE uniform disclosure form, all authors declare the following: Payment/services info: All authors have declared that no financial support was received from any organization for the submitted work. Financial relationships: All authors have declared that they have no financial relationships at present or within the previous three years with any organizations that might have an interest in the submitted work. Other relationships: All authors have declared that there are no other relationships or activities that could appear to have influenced the submitted work.

\section{References}

1. Sanchis-Gomar F, Perez-Quilis C, Leischik R, Lucia A: Epidemiology of coronary heart disease and acute coronary syndrome. Ann Transl Med. 2016, 4:256. 10.21037/atm.2016.06.33

2. Centers for Disease Control and Prevention: Prevalence of coronary heart disease-United States, 2006-2010. MMWR Morb Mortal Wkly Rep. 2011, 60:1377-1381.

3. Benjamin EJ, Blaha MJ, Chiuve SE, et al.: Heart disease and stroke statistics-2017 update: a report from the American Heart Association. Circulation. 2017, 135:e146-e603. 10.1161/CIR.0000000000000485

4. Berry JD, Dyer A, Cai X, et al.: Lifetime risks of cardiovascular disease . N Engl J Med. 2012, 366:321-329. 10.1056/NEJMoa1012848

5. Nsour M, Mahfoud Z, Kanaan MN, Balbeissi A: Prevalence and predictors of nonfatal myocardial infarction in Jordan. East Mediterr Health J. 2008, 14:818-830.

6. Zeidan RK, Farah R, Chahine MN, Asmar R, Hosseini H, Pascale Salameh P, Pathak A: Prevalence and correlates of coronary heart disease: first population-based study in Lebanon. Vasc Health Risk Manag. 2016, 12:75-84. 10.2147/VHRM.S97252

7. World Health Organization. Cardiovascular diseases (CVDs) . (2017). Accessed: November 27, 2019: https://www.who.int/news-room/fact-sheets/detail/cardiovascular-diseases-(cvds).

8. Mendis S, Puska P, Norrving B: Global Atlas on Cardiovascular Disease Prevention and Control . World Health Organization, Geneva; 2011.

9. Traina MI, Almahmeed W, Edris A, Tuzcu EM: Coronary heart disease in the Middle East and North Africa: current status and future goals. Curr Atheroscler Rep. 2017, 19:24. 10.1007/s11883-017-0659-9

10. Al Habib KF, Hersi A, Al Faleh H, et al.: Baseline characteristics, management practices, and in-hospital outcomes of patients with acute coronary syndromes: results of the Saudi project for assessment of coronary events (SPACE) registry. J Saudi Heart Assoc. 2011, 23:233-239. 10.1016/j.jsha.2011.05.004

11. Bugami SA, Rana B, Raneem H, et al.: Outcomes of percutaneous coronary intervention among patients with coronary artery disease in Saudi Arabia (single center study). J Cardiol Curr Res. 2019, 12:55-58.

12. Alhabib KF, Kinsara AJ, Alghamdi S, et al.: The first survey of the Saudi Acute Myocardial Infarction Registry Program: main results and long-term outcomes (STARS-1). PLoS One. 2019, 14:0216551. 10.1371/journal.pone.0216551

13. Jafary FH, Aslam F, Mahmud H, et al.: Cardiovascular health knowledge and behavior in patient attendants at four tertiary care hospitals in Pakistan - a cause for concern. BMC Public Health. 2005, 5:124. 10.1186/1471-2458-5-124

14. Rahman M, Akter S, Zohora FT, Shibly AZ: Public knowledge of cardiovascular disease and its risk factors in Tangail, Bangladesh: a cross-sectional survey. Int J Community Med Public Health. 2019, 6:1838-1842. 10.18203/2394-6040.ijcmph20191799

15. Almalki MA, Aljishi MN, Khayat MA, Bokhari HF, Subki AH, Alzahrani AM, Alhejily WA: Population awareness of coronary artery disease risk factors in Jeddah, Saudi Arabia: a cross-sectional study. Int J Gen Med. 2019, 12:63-70. 10.2147/IJGM.S184732

16. R Core Team: R: A Language and Environment for Statistical Computing . R Foundation for Statistical Computing, Vienna, Austria; 2017.

17. Ahmed AM, Hersi A, Mashhoud W, Arafah MR, Abreu PC, Al Rowaily MA, Al-Mallah MH: Cardiovascular risk factors burden in Saudi Arabia: the Africa Middle EastCardiovascular Epidemiological (ACE) study. J Saudi Heart Assoc. 2017, 29:235-243. 10.1016/j.jsha.2017.03.004

18. Bassiony MM: Smoking in Saudi Arabia. Saudi Med J. 2009, 30:876-881.

19. Mosca L, Jones WK, King KB, Ouyang P, Redberg RF, Hill MN: Awareness, perception and knowledge of heart disease risk and prevention among women in United States. Arch Fam Med. 2000, 9:506-515. 10.1001/archfami.9.6.506

20. Mosca L, Mochari H, Christian AH, et al.: National study of women's awareness, preventive action and barriers to cardiovascular health. Circulation. 2006, 113:525-534. 10.1161/CIRCULATIONAHA.105.588103

21. de Oliveira Castro YT, Rolim IL, Silva AC, Silva LD: Knowledge and meaning of cardiac catheterization from the perspective of cardiac patients. Rev Rene. 2016, 17:29-35. 10.15253/2175-6783.2016000100005

22. Tait AR, Voepel-Lewis T, Chetcuti SJ, Brennan-Martinez C, Levine R: Enhancing patient understanding of medical procedures: evaluation of an interactive multimedia program with in-line exercises. Int J Med Inform. 2014, 83:376-384. 10.1016/i.ijmedinf.2014.01.011 